\title{
A Study of Gestational Diabetes in Patients in a Tertiary Care Hospital in Hyderabad Telangana State, India
}

\author{
Md. Siddique Ahmed Khan ${ }^{1}$, K. S. Saraswathi' ${ }^{2}$, Farhana Aljabri ${ }^{3}$ and R. Shyamala ${ }^{4}$ \\ ${ }^{1}$ Department of Biochemistry, Shadan Institute of Medical Sciences and Research Centre, \\ Hyderabad, Telangana, India \\ ${ }^{2}$ Department of Obstetrics and Gynecology, Shadan Institute of Medical Sciences and Research \\ Centre, Hyderabad, Telangana, India \\ ${ }^{3}$ Department of OBGY, Shadan Institute of Medical Sciences, Hyderabad, Telangana, India \\ ${ }^{4}$ Department of Microbiology, Malla Reddy Medical College for women, Suraram, Hyderabad, \\ Telangana, India \\ *Corresponding author
}

\section{A B S T R A C T}

\begin{tabular}{|c|c|}
\hline $\begin{array}{l}\text { Ke e y w o or d s } \\
\text { GDM, Diagnostic criteria, } \\
\text { Screening tests, } \\
\text { Hyperglycemia, } \\
\text { complications, ADA - } \\
\text { American Diabetes } \\
\text { Association, IAD PSG - } \\
\text { (International Association } \\
\text { of Diabetes \& Pregnancy } \\
\text { Study Groups. }\end{array}$ & $\begin{array}{l}\text { Gestational Diabetes has been defined as any degree of glucose intolerance with an onset, } \\
\text { or first recognition during pregnancy (Beckmann et al., 2005). GDM affects between } 2 \% \\
\text { to } 5 \% \text { of pregnant women. Increasing levels of plasma glucose are associated with birth } \\
\text { weight above the } 90^{\text {th }} \text { percentile, and primary caesarean deliveries and neonatal } \\
\text { hyperglycemia. Risk factors for GDM include a history of macrosomia, strong family } \\
\text { history of diabetes, and obesity. There is a lack of uniform strategy for screening and } \\
\text { diagnosing GDM globally. Some recommend a universal approach, whereas others exempt }\end{array}$ \\
\hline Article Info & morbidity for both the mother and the \\
\hline $\begin{array}{l}\text { Accepted: } \\
\text { 23 September } 2017 \\
\text { Available Online: } \\
10 \text { October } 2017\end{array}$ & $\begin{array}{l}\text { GDM should be initially treated with diet \& exercise. If these do not control the sugar } \\
\text { levels, then insulin should be initiated. It is generally recommended that pregnancies } \\
\text { complicated by GDM do not go beyond term. }\end{array}$ \\
\hline
\end{tabular}

\section{Introduction}

Normally pregnancy induces a diabetogenic response in the individual, as the insulin requirements during pregnancy are increased. It starts from the third month and continues till term. The reasons given for the increase are -

The very large increase in insulin antagonising hormones like human placental lactogen, progesterone, and cortisol and
The production of enzymes- placental insulinase - by the placenta that increases the degradation of insulin.

Complications seen in diabetic pregnancies are both on the mother and the foetus.

Maternal complications include Pregnancy Induced Hypertension, Maternal Infections especially - Urinary Tract Infection, Abortion, 
Preterm labour, Hydramnios, Risk of Abruptio Placenta, 10\% risk of developing type II diabetes.

Foetal complications are mainly foetal malformations like Neural tube defects, Cardiac anamolies such as transposition of great vessels, Ventricular Septal Defect, Atrial Septal Defect, Caudal regression specific to diabetes, Unexplained foetal death, Foetal macrosomia, Foetopelvic disproportion, Shoulder dystocia, and still birth (Acher et al., 1985).

Screening tests are essential for the detection of Gestational Diabetes

Risk factors for screening for Gestational Diabetes - are Diabetes in a first degree relative, Maternal obesity > $120 \%$ of body weight, Previous large baby $>4 \mathrm{~kg}$, Previous unexplained still births, Previous abnormal GTT, Hydramnios or macrosomia in the present pregnancy. An Asian ethnic background is a risk factor - hence all Indian women should be screened.

Screening test for Diabetes in pregnancy are O'Sullivan test or oral glucose challenge test Performed between 24 to 28 weeks of pregnancy. In this procedure 50 gm glucose given Plasma glucose measured 1 hour later with out regard to the time of the day or the last meal.

A value of $140 \mathrm{mg} / \mathrm{dl}$ or higher will identify women with Gestational Diabetes.

Glucose Tolerance Test is done when screening is positive or index of suspicion is very high One does not want a 2 step procedure.

\section{Oral GTT}

Previous day normal diet is taken.
A fasting blood sample is taken for glucose estimation

$\mathrm{Pt}$ is given $100 \mathrm{gm}$ glucose in $200 \mathrm{ml}$ of water orally

Venous blood samples collected at the end of $1 \mathrm{hr}, 2 \mathrm{hr}$ and $3 \mathrm{hrs}$

Any result with 2 or more abnormal values are diagnostic of Gestational Diabetes.

\section{Management of gestational diabetes}

This aims at control of Diabetes, Obstetric management, timing of delivery, and proper care of the newborn.

The cornerstone of management is glycemic control (Marion, 2008). Close monitoring of the blood sugar is important.

\section{Management will be to maintain}

A fasting level of $<95 \mathrm{mg} / \mathrm{dl}$

Post prandial level of $<140 \mathrm{mgm} / \mathrm{dl}$ at $2 \mathrm{hrs}$

And $<120 \mathrm{mgm} / \mathrm{dl}$ at $1 \mathrm{hr}$

Some patients need hospitalisation to keep them in good control.

Every patient should be tested for ketone bodies. Blood sugar control can be achieved by diet alone. Or diet along with insulin injection.

Moderate exercise of 30 minutes daily is advised. - exercise has been shown to improve glycemic control (Gavard et al., 2008).

Quality nutritional intake is essential.

Diet in pregnant diabetes. $-30-35 \mathrm{kcal}$ per $\mathrm{kg}$ of ideal body weight 
Is given as 3 meals and 3 snacks daily. Out of this $55 \%$ carbohydrates, $20 \%$ proteins and $25 \%$ fats with less than $10 \%$ saturated fat. Patients with GDM who cannot control their glucose levels with di et al., one will require insulin (Crowther et al., 2005).

Non-Insulin antihyperglycemic agent therapy with Glyburide and Metformin have been used in Europe \& South Africa in pregnancy for many years without reported adverse effects on the foetus (Elliot et al., 1991).

Intrapartum care should aim at regular antenatal checkups, to keep the patient under good glycemic control. Some studies suggest induction of labour at 38-39 weeks in case of insulin treated Gestational Diabetes Mellitus patients, or when ultrasound exam shows signs of foetal macrosomia (Lurie et al., 1996).

During labour and delivery the aim is to maintain normoglycemia, i.e., blood glucose level between $72-26 \mathrm{mgm} / \mathrm{dl}$ in order to prevent neonatal hypoglycaemia. Postpartum care includes monitoring of glucose level 24 72 hours after delivery. $95 \%$ of them will return to a completely normal glucose status, and they should be able to have a normal diet. OGTT is performed within 6- 12 weeks after delivery.

\section{Materials and Methods}

In our study universal screening is done in Antenatal clinic of shadan Institute of medical sciences patients were selected and after taking their consent. A 1hour glucose challenge test was done at $24-28$ weeks of gestation. For this test patient given 50 gms of oral glucose. 1 hour later. blood is drawn for plasma glucose level. In our centre we used $140 \mathrm{mg} / \mathrm{dl}$ as cut off point. A value above $140 \mathrm{mg} / \mathrm{dl}$ is considered abnormal. And a second test $3 \mathrm{hr}$ glucose tolerance test was done.
In 2010 March the ADA published new recommendations for screening and diagnosis of GDM. The IADPSG recommend universal screening for Gestational Diabetes. It recommends universal screening pregnant women for GDM.

If the initial screening is negative, the IADPSG recommends universal screening to be performed at 24-28 weeks of gestation with a 2- hour, 75 gram of OGTT the one step approach. GDM is diagnosed if 1 or more values equal or exceeds thresholds;

FPG $(5.1 \mathrm{mmol} / \mathrm{L})(92 \mathrm{mgm} / \mathrm{dl})$

1hr Plasma glucose (10mmol/L) (180mgm/dl)

$2 \mathrm{hr}$ plasma glucose $(8.5 \mathrm{mmol} / \mathrm{L})$ (153mgm/dl).

The OGTT is performed after fasting overnight for 8-14 hours, and not reducing the usual carbohydrate intake for the preceding several days.

The American Association of Obstetricians and Gynaecologists (ACOG) (Committee on Practice Bulletins) and the National Institute of Health (National Institute of Health Consensus ), still recommend the traditional 2 - step approach, in which an initial screening between 24-28 weeks by 50 gram oral glucose challenge test (GCT) and measuring the plasma glucose concentration after 1 hour. For those women who exceeded the glucose threshold of $\geq 7.2$, or $\geq 7.8 \mathrm{mmol} / \mathrm{L}(130$ or $140 \mathrm{mgm} / \mathrm{dl}$ ) on OCT; a diagnostic 3 - hour $100 \mathrm{~g}$ of oGTT is recommended.

\section{Results and Discussion}

2025 antenatal cases with gestational age between 24 to 28 weeks were screened. This was in the period between January 2013 to December 2016. Out of these 2025patients 81 
were positive with blood sugar level of more than $140 \mathrm{mg} / \mathrm{dl}$ accounting for $4 \%$.

Pregnancy confers a state of insulin resistance and hyperinsulinaemia that may predispose some women to develop diabetes. Gestational diabetes mellitus occurs when a women's pancreatic function is not sufficient to overcome the diabetogenic environment of Pregnancy. In the United States, prevalence rates for GDM are higher for African American, Hispanic, American Indian, and Asian women than for white women (BenHaroush et al., 2004). The prevalence of GDM in the United States varies from $1.4 \%$ to $14 \%$. Most commonly GDM affects $2 \%$ and $5 \%$ of pregnant women. In my study the incidence was noted to be $4 \%$. The amount of GDM varies in direct proportion to the prevalence of type II diabetes (Catalano et al., 2006).

They are 2 different methods of classifying diabetes in pregnancy. The first is the White classification and the second is American Diabetes Association (ADA) classification (Ferrara, 2007).

GDM is a problem which effects of women during pregnancy and it can have lasting effects on the health of both the mother and the baby. Proper screening, diagnosis and management of hyperglycemia are critical to minimise these complications.

Risk factors for GDM include a history of obesity, age $>25$, history of macrosomia.

The cut off values for diagnosing gestational diabetes as given by Carpenter and Coustan the national diabetes data GP are as follows

\begin{tabular}{|l|l|l|}
\hline & Carpenter and Coustan & NDDG \\
\hline Fasting & 95 & 105 \\
\hline $1 \mathrm{hr}$ & 180 & 190 \\
\hline $2 \mathrm{hr}$ & 155 & 165 \\
\hline $3 \mathrm{hr}$ & 140 & 145 \\
\hline
\end{tabular}

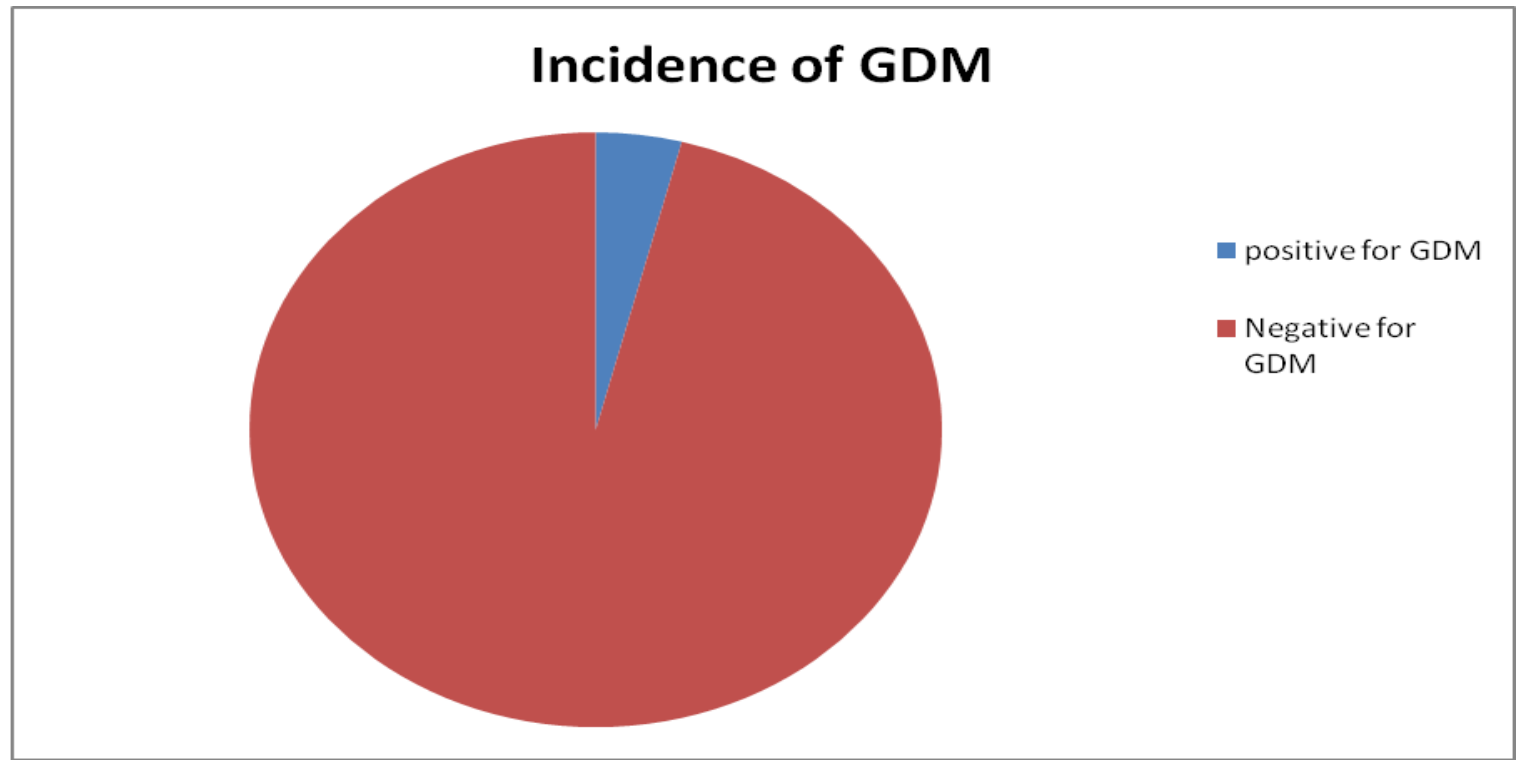


There is a debate regarding the preferred screening protocol for GDM - whether it is universal screening or selective screening.

Increasing levels of blood sugar are associated with macrosomia, primary caesarean deliveries and neonatal hypoglycaemia. Pregnancies complicated by GDM do not go beyond term. Glycemic control is the main key point in management of GDM.

In conclusion, the prevalence of GDM is raising worldwide parallel to the increment in the prevalence of Type 2 Diabetes Mellitus and Obesity. GDM is associated with maternal and neonatal adverse outcomes. Maintaining adequate blood glucose levels in GDM reduces morbidity for both mother and baby. Worldwide, there is a lack of uniform strategies for screening \& diagnosing GDM. Hence there is a need to standardise the screening and diagnostic criteria for GDM universally.

Treatment of GDM consists of diet and exercise. Insulin is initiated when these measures fail to achieve glycemic control. The use of Oral Hypoglycemic agents in pregnancy may shift the paradigm in treatment of GDM.

\section{References}

Acker, D.B., Sachs BP, et al., Risk factors for shoulder dystocia. Obstet Gynecol. 1985; 66: 762-768.

Beckmann, C.R.B., Ling FW, Smith RP, et al., editors. Obstetrics and Gynecology. $5^{\text {th }}$ ed.
Philadelphia, PA: Lippincott Williams \& Wilkins; 2005.

Ben - Haroush, A., et al., Epidemiology of gestational diabetes mellitus and its association with type 2 diabetes. Diabet Med. 2004; 21: 103-113

Catalano, P.M., etal. the short and long term implications of maternal obesity on the mother and her offspring. BJOG. 2006; 113: 1126-1133.

Committee on Practice Bulletins - Obstetrics. Practice Bulletin No. 137 : Gestational Diabetes mellitus. Obst Gynecol. 2013; 12:406-416.

Crowther, C.A., Hiller JE, etal for Australian Carbohydrate Intolerance study in Pregnant women (ACHOIS) Trial Group, authors. Effect of treatment of gestational diabetes mellitus on pregnancy outcomes. $\mathrm{N}$ Engl $\mathrm{J}$ Med. 2005; 352: 2477-2486.

Elliot, B.D., Langer O, Schenker S, Johnson RF. Insignificant transfer of glyburide occurs across the human Placenta. Am J Obstet Gynecol. 1991; 165: 807-812.

Ferrara, A. Increasing prevalence of gestational diabetes mellitus: a public health perspective. Diabetes Care. 2007; 30 suppl 2: S141-S146

Gavard, J.A., et al., Effect of exercise on pregnancy outcome. Clin Obstet Gynecol. 2008; 51: 467-480

Lurie, S., Insler V, Hagay ZJ. Induction of labor at 38 to 39 weeks of gestation reduces the incidence of shoulder dystocia in gestational diabetic patients class A2. Am J Perinatol. 1996; 13: 293-296.

Marion, D.W. Treatment and course of gestational diabetes mellitus (Accessed August 29, 2008).

National Institutes of Health consensus development conference statement: diagnosing gestational diabetes mellitus, March 4-6, 2013. Obstet Gynecol. 2013; 122:358-369.

\section{How to cite this article:}

Md. Siddique Ahmed Khan, K.S. Saraswathi, Farhana Aljabri and Shyamala, R. 2017. A Study of Gestational Diabetes in Patients in a Tertiary Care Hospital in Hyderabad Telangana State. Int.J.Curr.Microbiol.App.Sci. 6(10): 2586-2590. doi: https://doi.org/10.20546/ijcmas.2017.610.304 